\title{
A biological forecasting system to control Black Leaf Streak disease of bananas and plantains
}

\author{
Éric FOURÉ ${ }^{1}$, Jacky GANRY ${ }^{2 *}$
}

${ }^{1}$ CIRAD, UPR Syst. Cult. Banan. Plantains Ananas, Blvd. la Lironde, TA B-26 / PS4, 34398 Montpellier Cedex 5

2 CIRAD, UPR Prod. Fruit. Intégr., TA B-77 / PS4, 34398 Montpellier Cedex 5, France jacky.ganry@cirad.fr

${ }^{*}$ Correspondence and reprints

Fruits, 2008, vol. 63, p. 311-317 (C) 2008 Cirad/EDP Sciences All rights reserved DOI: 10.1051/fruits:2008029 www.fruits-journal.org

\author{
A biological forecasting system to control Black Leaf Streak disease of \\ bananas and plantains.
}

Abstract - Introduction. This protocol aims at monitoring the development of Black Leaf Streak (Mycosphaerella fijiensis Morelet) disease of banana plants in order to control this disease with a minimum of fungicide applications. A good timing of fungicide application will result in lower cost of control, lower risk of fungicide resistance and lower environmental negative impact. The principle, key advantages, starting plant material and expected results are presented. Materials and methods. Details of the six steps of the protocol allowing banana plot preparation, data collection, stage of evolution of the disease (SED) calculation, and timing of fungicide applications are described. Possible troubleshooting is mentioned. Results. Weekly observation of selected banana plants allows filling in a data sheet used for the calculation of the SED. A graphic representation of the weekly evolution of this SED can then be used for timing of fungicide spraying decisions.

Cameroon / Musa sp. / methods / disease control / Mycospbaerella fijiensis / agricultural warning services

\begin{abstract}
Un système d'avertissement biologique pour le contrôle de la maladie des raies noires chez les bananiers et plantains.

Résumé - Introduction. Ce protocole permet de quantifier le développement de la maladie des raies noires (Mycosphaerella fijiensis) du bananier pour contrôler chimiquement cette maladie avec un minimum d'applications de fongicide. Une bonne programmation de l'application des molécules fongicides permettra de diminuer le coût du contrôle, le risque de voir apparaître des souches de $M$. fijiensis résistantes aux fongicides, et l'impact négatif des traitements sur l'environnement. Le principe, les principaux avantages, le matériel végétal de départ, et les résultats attendus de la méthode sont présentés. Matériel et méthodes. Le détail des six étapes de réalisation du protocole permettant la préparation de parcelles en bananeraie, la collecte de données, le calcul de l'état d'évolution de la maladie (EEM) et la programmation de l'application des fongicides est décrit. De possibles problèmes sont évoqués. Résultats. L'observation hebdomadaire des bananiers choisis permet de remplir une fiche de données utilisée pour le calcul de l'EEM. Une représentation graphique de l'évolution hebdomadaire de cet EEM peut être alors utilisée pour programmer l'application des fongicides.
\end{abstract}

Cameroun / Musa sp. / méthode / contrôle de maladies / Mycosphaerella fijiensis / avertissement agricole

\section{Introduction}

\section{Application}

This protocol aims at monitoring the development of Black Leaf Streak disease
(Mycosphaerella fijiensis) in order to control this disease with a minimum of fungicide applications. Good timing of fungicide application will result in lower cost of control, lower risk of fungicide resistance and lower environmental negative impact. 


\section{Principle}

The biological forecasting system is based on the early detection of new attacks through the calculation of the Stage of Evolution of the Disease (SED). This SED represents the speed of evolution of the disease, which reflects the climatic conditions and the intensity of the infection [1-3]. The observation of new attacks detected on young leaves will allow blocking their evolution towards necroses by a possible application of fungicide. If the climatic conditions are very favourable to the development of the disease, the first symptom will appear on leaf No. 2, considering that the Foliar Emission Rate (FER) is one leaf per week. If the climatic conditions are less favourable, the first symptom will be observed either on leaf No. 3, or on older leaves. In adverse conditions, no symptom might develop following leaf infection. Consequently, there is a gradient of evolution of the disease from the top to the bottom of the banana tree. Lastly, in order to maintain field inoculum as low as possible, it is essential to stop the disease before necrotic formation occurs: sexual sporulation starts in necrotic stages of the disease. This is why our method focuses on early detection of new attacks of the disease. This method is derived from the method developed for Sigatoka disease control [4]. However, SED calculation is not the same for Sigatoka disease and Black Leaf Streak disease. Thus, in order to avoid any confusion on the complex determination of SED, the forecasting methods of the two diseases are published in two separate articles of this journal.

\section{Key advantages}

The forecasting system to control Black Leaf Streak disease is effective on bananas and plantains, and it has been successfully developed in different places [3, 5].

\section{Starting material}

The estimation of the Stage of Evolution of the Disease (SED) requires a banana plot of ten homogenous young banana trees with eight to ten leaves and the installation of $n$ plots for observation, $n$ depending on the plantation surface.

\section{Time estimation}

For evaluation of the disease on ten plants, the time required is $15 \mathrm{~min}$ (transportation to field is not included). For calculation of SED and graphic representation: $15-30 \mathrm{~min}$ manually, but $5 \mathrm{~min}$ if a computer is used.

\section{Expected results}

The application of the method allows monitoring of the disease and obtaining an element of decision for a new fungicide application according to the speed of evolution of the disease.

\section{Materials and methods}

\subsection{Protocols}

\section{Banana plot preparation}

- Step 1

Choice and first observation of the plants:

- Two months after the plantation of the plot, select 10 banana plants.

- The day of the first observation, examine for each plant the total number of leaves and score this number on the first unfurled leaf. Identify and number these 10 plants in order to observe them every week.

Note: the evaluation of symptoms has to be done preferably on unflowered plants, so it is advised to maintain the 10 young banana trees by re-planting 20 new banana trees (suckers, bulbs or vitroplants) every 34 months. In this way, at the flowering of the initial 10 banana trees observed for SED evaluation, it is possible to move the observation to young plantings. For a good continuity and reliability of information, the banana plot must be localised in the same geographic place all the time. The information of this plot will account for disease development for an area of 20-200 ha according to the uniformity of the area. 


\section{Data collection}

\section{- Step 2}

Organisation of the data sheet:

- Prepare a data sheet (table Ia). Use a new data sheet for each data collection.

- Note numbers of banana trees into the column BTN.

- From the previous data sheet (normally, one week before), note the number of leaves of each banana plant into the column OLN.

- From the previous data sheet (normally, one week before), note the cigar stage of each banana plant into the column OCS according to the five stages of Brun's scale [10] (figure 1). According to this scale the following values are attributed to each stage: stage 0 corresponds to 0 leaf; stage 2 , to 0.2 leaf; stage 4 , to 0.4 leaf; stage 6 , to 0.6 leaf; stage 8 , to 0.8 leaf.

- Step 3

Observation of the disease on banana leaves:

- Observe the leaves No. 2 to No. 4 of the banana tree every week, and score the most advanced stage of the disease according to Fouré's scale [6-9] as follow:

(1) Stage 1: a spot is just visible to the naked eye as a minute yellowish speck inferior to $1 \mathrm{~mm}$ only on the underside of the leaf.

(2) Stage 2: red or brown streaks (rust coloured) are visible firstly on the underside of the leaf, then on both sides. These streaks become progressively brown on the underside and black on the upper side of the leaf. The first outward sign of this stage 2 on the upper side of the leaf is a yellow streak which becomes progressively brown.

(3) Stage 3: widening and extension of the stage 2 .

(4) Stage 4: this is the spot stage. The spot takes a circular or elliptical form.

(5) Stage 5: this corresponds to the first of the two necrotic stages; a yellow halo firstly surrounds a black spot.

(6) Stage 6: this corresponds to the second necrotic stage; drying out of the centre of the spot is observed, spots progressively take a grey colour, but keep a black halo also surrounded by yellow.
- Estimate lesion density by the negative value "-" if there are less than 50 outward signs (taking into account all stages), and by the positive value " + " if there are more than 50 outward signs (taking into account all stages).

- For each banana tree, copy the most advanced stages and the corresponding lesion density for all No. 2 to No. 4 leaves into the columns corresponding to the leaf number (table Ia).

- Step 4

Observation of the banana plant:

- A week later, for each plant, observe the number of the last unfurled leaf and copy the number of leaves into the column NLN of the data sheet (table Ia).

- For each plant, note the stage of cigar development according to the five stages of Brun's scale [10] (figure 1).

- Copy the cigar stage number into the column (NCS) of the data sheet (table Ia).

\section{Stage of evolution of the disease (SED) calculation}

A coefficient is attributed to each different [(leaf number)-(stage of the disease)] association. This coefficient is characteristic of the speed of evolution of the disease [3] (table II).

Note: for the same leaf, the faster the development of the disease, the higher the value of the stage of the disease. Therefore, the value of the coefficient increases with the value of the stage of the disease. For the same stage of the disease, the faster the development of the disease, the lower the number of the leaf. So, the value of the coefficient decreases with the number of the leaf.

\section{- Step 5}

Determine the Stage of Evolution of the Disease (SED) as a successive calculation of several intermediates:

- The disease stage is divided into six classes (Fouré's scale, cf. step 3). The frequency of disease stage appearance at a given lesion density (table Ia) is scored for each leaf in the columns corresponding to 


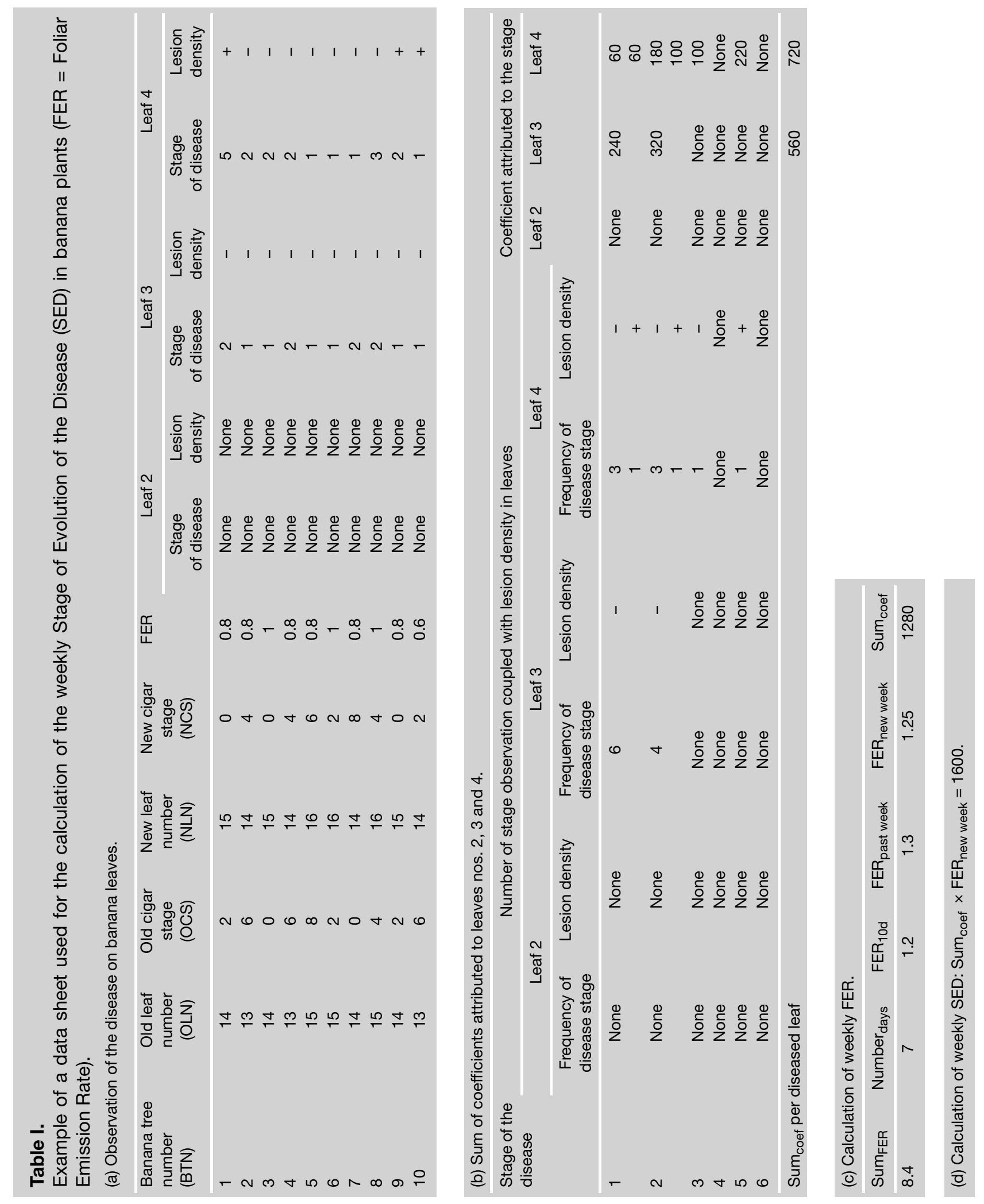


leaf no. 2, leaf No. 3 and leaf No. 4 (table Ib).

- For each frequency, multiply this value by the coefficient value corresponding to the stage and the density sign of the lesions (table II). Score the result in the columns of the data sheet corresponding to the coefficient attributed to the leaf No. 2, leaf No. 3 and leaf No. 4 (table Ib).

- Sum all the values in the columns corresponding to each leaf No. 2, leaf No. 3 and leaf no. 4 coefficient, and then score these values into the line Sum coef $_{\text {of the data sheet }}$ (table Ib).

- Calculate the Foliar Emission Rate of the new week $\left(\mathrm{FER}_{\text {new week }}\right)$. On the data sheet, proceed as follows (table Ic):

(1) In the column FER (table 1a), for lines 1 to 10 , calculate the values of the FER as $\{\mathrm{FER}=[(\mathrm{NLN})+0.1 \times(\mathrm{NCS})]-[(\mathrm{OLN})+$ $0.1 \times(\mathrm{OCS})\}$.

Caution: at each new weekly observation, the values of columns (NLN) and (NCS) become the values reported in (OLN) and (OCS).

(2) Sum all values from line 1 to 10 of the column FER to obtain Sum $\mathrm{FER}$ (table Ic).

(3) Note the number of days Number days $_{\text {s }}$ between the old and the new observations, ordinarily $7 \mathrm{~d}$ (table Ic).

(4) Calculate $\mathrm{FER}_{10 \mathrm{~d}}$, the foliar emission rate for $10 \mathrm{~d}$ as $\left[\mathrm{FER}_{10 \mathrm{~d}}=\left(\operatorname{Sum}_{\mathrm{FER}} \times 10\right) /\left(\mathrm{N}_{\mathrm{ba}}\right.\right.$ nanas $\times$ Number $_{\text {days }}$, where $\mathrm{N}_{\text {bananas }}$ is the number of banana trees (ordinarily 10).

(5) Calculate $\mathrm{FER}_{\text {new week }}$ as $\left[\mathrm{FER}_{\text {new week }}=\right.$ $\left(\mathrm{FER}_{\text {past week }}+\mathrm{FER}_{10 \mathrm{~d}}\right) / 2$ ], where $\mathrm{FER}_{\text {past }}$ week is the foliar emission rate of the past week.

- Make the correction by the Foliar Emission Rate (FER) in order to express the Stage of Evolution of the Disease (SED) as a speed value and to take into account that the more vigorous the growth of the banana trees, the faster the disease evolution [11]: SED = Sum $_{\text {coeff }} \times$ FER $_{\text {new week }}$.

\section{Timing of fungicide applications}

- Step 6

Make a graphic representation of the weekly evolution of SED, and use this graphic representation for timing of spraying decisions.

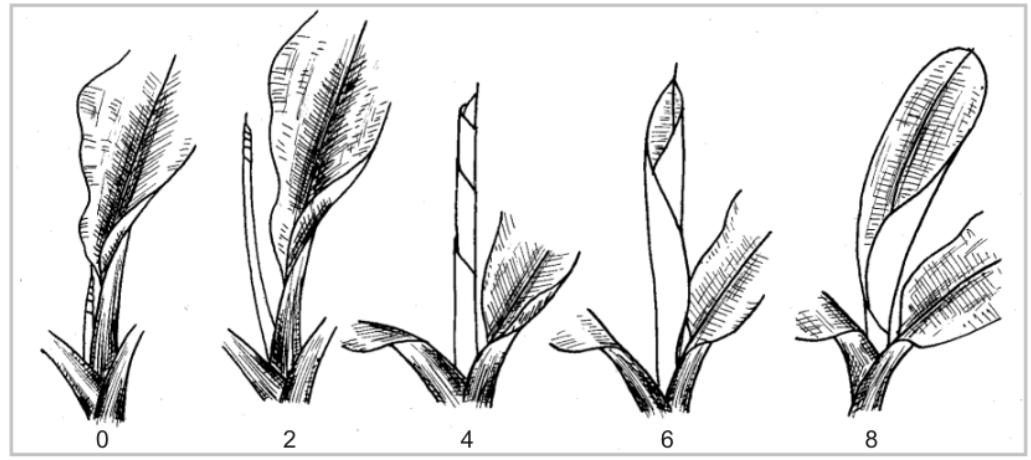

Note: the decision for a new fungicide application will be decided according to the trend of the SED curve (figure 2). After a fungicide treatment, the curve decreases and no funFigure 1.

Brun's scale of cigar development in the banana plant development [11]. gicide application will be decided until a significant rise of the curve is observed.

\subsection{Troubleshooting}

Frequent replanting of the observation plot is necessary for reliable information determination. However, several factors can affect the efficiency of the control based on

\section{Table II.}

Coefficients attributed to the different [(leaf number)-(stage of the disease)] associations for banana trees affected by the Black Leaf Streak disease of bananas and plantains [3].

\begin{tabular}{lcccc}
$\begin{array}{l}\text { Stage of the } \\
\text { disease }^{1}\end{array}$ & $\begin{array}{c}\text { Density of } \\
\text { lesions }\end{array}$ & No. 2 & No. 3 & No. 4 \\
\hline 1 & - & 60 & 40 & 20 \\
& + & 100 & 80 & 60 \\
2 & - & 100 & 80 & 60 \\
& + & 140 & 120 & 100 \\
3 & - & 140 & 120 & 100 \\
& + & 180 & 160 & 140 \\
4 & - & 180 & 160 & 140 \\
& + & 220 & 200 & 180 \\
5 & - & 220 & 200 & 180 \\
6 & + & 260 & 240 & 220 \\
& - & 260 & 240 & 220 \\
& + & 300 & 280 & 260
\end{tabular}

${ }^{1}$ For each stage of the disease, the mark attributed depends on density of lesions, which is estimated by "-" if there are less than 50 outward signs and by "+" if there are more than 50 outward signs. 


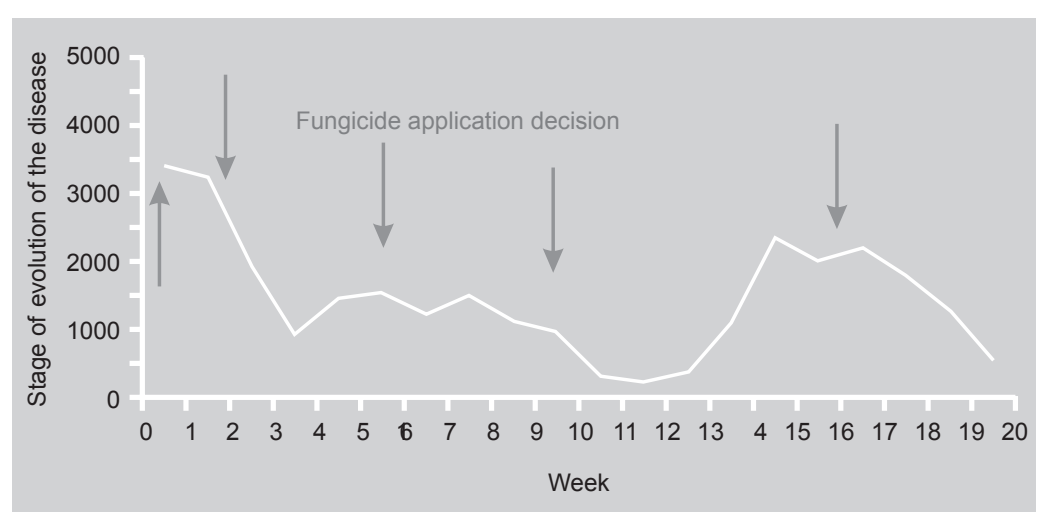

Figure 2.

Weekly variations in the stage of evolution of the Black Leaf Streak disease of bananas and plantains, and time proposed for fungicide application.

this forecasting method. This troubleshooting will be detected by the following evolution of the curve after a fungicide application:
- no decrease in the curve is observed,

- the time between two rises of the curve is very short.

The success of this control strategy relies on several aspects such as timing of applications, fungicide treatments used and global organisation of the control [12].

\section{Timing of applications}

The time between decision and execution of one application should not exceed $2 \mathrm{~d}$ and the whole spraying area should be sprayed on the same day. Treatments are carried out by aeroplane, helicopter, or by backpack sprayer on small surfaces. However, care must be taken with the climatic conditions of aerial spraying: only a small window, early in the morning and late in the afternoon, is suitable; otherwise, thermal inversion and air turbulence do not allow correct spray deposition. Aerial application is not possible on rainy and windy days. Logistics available for aerial sprayings are therefore essential to optimise spraying during this small window.

\section{Treatment efficiency}

The efficiency of treatments is dependent on the quality of the foliar application. A good coverage is also indispensable. Bad weather conditions on the day of application, an irregular topography of the zone or the pres- ence of obstacles might alter the uniformity of the treatment. The use of mineral oils as a carrier considerably improves the quality of coverage through aerial spraying with low volumes (12-15 L $\mathrm{ha}^{-1}$ ). A strong synergy between the aerial spraying companies and the banana growers is also important to ensure the quality of the aerial applications.

The efficiency of treatments relies on a strong curative effect. Thus, systemic fungicides (antimitotics, sterol inhibitors of group 1 and 2, strobilurins) are preferred to contact fungicides. The use of these fungicides in pure oil strengthens their curative effect, because mineral oils are fungistatic. Attention should be paid to the formulation of the fungicide used. Only formulations compatible with pure oil should be used. Phytotoxic effects of the oil have to be preliminarily determined. Fungicide concentration must also be determined according to preliminary field experiments.

Special attention should be paid to managing the possible fungicide resistance that might develop following the repetitive use of unisite fungicides. Alternation between different groups of fungicides, or mixtures with contact fungicides, is essential to delay the emergence of such resistance.

Keeping the sources of inoculum at a very low level is also important to ensure good efficiency of treatments. Where extensive spotting is present, new infections will develop quickly because chemical sprays do not eliminate the disease from spotted leaves and the only solution is to remove them mechanically from the banana tree.

\section{Organisation of control}

Since ascospores are transported by wind over long distances, the control strategy should be the same in all banana plantations to prevent any disruption. The organisation of the treatments is more efficient when a centralisation of the decision is performed by a unique technical service operating according to rational guidelines rather than if each grower implements his own strategy. Centralisation of decisions and operations is essential and the banana growers should be grouped in an association that would perform the control strategy. 


\section{Typical results obtained}

Weekly observation of the ten banana plants selected in a plot allows filling in the data sheet used for the calculation of the Stage of Evolution of the Disease (SED) (table I). A graphic representation of the weekly evolution of this SED is then used for timing of spraying decisions (figure 2).

\section{References}

[1] Ganry J., Meyer J-P., La lutte contrôlée contre le Cercospora aux Antilles. Bases climatiques de l'avertissement; technique d'observation et de numérotation de la maladie, Fruits 27 (1972) 767-774.

[2] Ganry J., Laville E., Les cercosporioses du bananier et leurs traitements. 1. Traitements fongicides. 2. Avertissement, Fruits 38 (1983) 3-20.

[3] Fouré É, Stratégies de lutte contre la cercosporiose noire des bananiers et plantains provoquée par Mycosphaerella fijiensis Morelet. L'avertissement biologique au Cameroun. Évaluation des possibilités d'amélioration, Fruits 43 (1988) 269-274.

[4] Ganry J., de Lapeyre de Bellaire L., Mourichon X., A forecasting system to control Sigatoka disease, Fruits 63 (6) (2008), in press.

[5] Mouliom-Pefoura A., Lassoudière A., Mise au point d'un système d'avertissement biologique pour la lutte contre Mycosphaerella fijiensis Morelet, agent de la cercosporiose noire dans les bananeraies camerounaises, Sémin. WARCOP, Libreville, Gabon, 1984, $17 \mathrm{p}$.

[6] Fouré É., Les cercosporioses du bananier et leurs traitements. Comportement des var- iétés. Études de la sensibilité variétale des bananiers et plantains à Mycosphaerella fijiensis Morelet au Gabon (maladie des raies noires). I. Incubation et évolution de la maladie, Fruits 37 (1982) 749-759.

[7] Fouré É, Grisoni M., Zurfluh R., Les cercosporioses du bananier et leurs traitements. Comportement de variétés. Études de la sensibilité variétale des bananiers et plantains à Mycosphaerella fijiensis Morelet et de quelques caractéristiques biologiques de la maladie des raies noires au Gabon, Fruits 39 (1984) 365-378.

[8] Fouré É, Varietal reactions of bananas and plantains to black leaf streak disease, in: Persley G.J., de Langhe E.A. (Eds.), Banana and plantain breeding strategies, ACIAR Proc. No. 21, Canberra, Australia, 1987, pp. 110-113.

[9] Carlier J., Fouré É, Gauhl F., Jones D.R., Lepoivre P., Mourichon X., Pasberg-Gauhl C., Romero R.A., Fungal diseases of the foliage, Sigatoka leaf spots: Black Leaf Streak, in: Jones D.R. (Ed.), Diseases of banana, abaca and enset, CABI Publ., UK, 2000, pp. 37-79.

[10] Brun J., Études préliminaires sur l'utilisation des variétés de bananiers résistants dans la lutte contre la cercosporiose, Fruits 17 (1962) 113-119.

[11] Brun J., La cercosporiose du bananier en Guinée. Étude de la phase ascosporée de Mycosphaerella musicola Leach., Univ. Orsay, Thèse, Paris, France, 1963.

[12] De Lapeyre de Bellaire L., Mourichon X., Ganry J., A forecasting system for regulated control of Sigatoka Disease of bananas in Guadeloupe, in: Proc. Crop protection and food quality, meeting customer needs, ANPP-BCPC, Univ. Kent, Canterbury, UK, 1997, pp. 189-196. 